\title{
Effect of antioxidant of bamboo leaves on gene expression associated with mouse embryonic fibroblast reproduction and embryonic development
}

\author{
FENG YU ${ }^{1}$, XIAOWEI QIAN ${ }^{1}$, ZHANGHUI ZENG ${ }^{1}$, XIAOLI ZHAO ${ }^{1}$, RONG HOU ${ }^{2}$, ZHIHE ZHANG $^{2}$, \\ HONGWU BIAN $^{1}$, NING HAN ${ }^{1}$, JUNHUI WANG ${ }^{1}$ and MUYUAN ZHU ${ }^{1}$ \\ ${ }^{1}$ Key Laboratory for Cell and Gene Engineering of Zhejiang, College of Life Sciences, Zhejiang University, \\ Hangzhou, Zhejiang 310012; ${ }^{2}$ The Key Laboratory for Conservation Biology of Endangered Wildlife, \\ Chengdu, Sichuan 610081, P.R. China
}

Received October 28, 2016; Accepted July 12, 2017

DOI: $10.3892 / \mathrm{mmr} .2017 .7505$

\begin{abstract}
Antioxidant of bamboo leaves (AOB) was certified to be a natural antioxidant by the Chinese Ministry of Health in 2003. However, the effects of AOB on animal reproductive and developmental functions remain unclear. The present study aimed to investigate the effects of different concentrations of AOB on mouse embryonic fibroblast (MEF) cells, and to examine the underlying molecular mechanism through which AOB affects the proliferation and apoptosis of MEFs. MEFs prepared from individual embryos were treated with various dosages of AOB. Cell viability and apoptosis were detected by MTT and flow cytometry assays, respectively. Reverse transcription-quantitative polymerase chain reaction and western blot analyses were used for the detection of mRNA and protein expression. Functional annotation of differentially-expressed genes was performed according to the Gene Ontology database and Kyoto Encyclopedia of Genes and Genomes pathway analysis. Compared with the control group, $\sim 50 \%$ of $\mathrm{MEF}$ cells were inhibited following treatment with a $400 \mu \mathrm{g} / \mathrm{ml}$ concentration of AOB. Treatment with $400 \mu \mathrm{g} / \mathrm{ml}$ AOB for $72 \mathrm{~h}$ significantly increased the apoptotic rate of MEF cells compared with the control group. Following treatment with AOB, dehydrogenase/reductase 9, phospholipase A2 group IVE and platelet derived growth factor B were downregulated, while 17 other genes were upregulated in MEF cells. Treatment with AOB markedly increased the expression of phosphorylated extracellular signal-regulated kinase (ERK), $\beta$-catenin, transcription factor SOX-17,
\end{abstract}

Correspondence to: Dr Muyuan Zhu or Dr Xiaoli Zhao, Key Laboratory for Cell and Gene Engineering of Zhejiang, College of Life Sciences, Zhejiang University, 866 Yuhangtang Road, Xihu, Hangzhou, Zhejiang 310012, P.R. China

E-mail: muyuanm_zhu@163.com

E-mail: zhaoxiaoli@zju.edu.cn

Key words: antioxidant of bamboo leaves, mouse embryonic fibroblast, proliferation, apoptosis, reproduction, signaling pathway calcium-binding tyrosine phosphorylation-regulated protein, and cholesterol side chain cleavage enzyme mitochondrial $(\mathrm{P}<0.01)$. Additionally, the ERK pathway inhibitor U0126 and Wnt pathway inhibitor dickkopf-related protein 1 markedly suppressed the expression of the above genes $(\mathrm{P}<0.01)$. AOB may impact the expression of proteins associated with embryonic fibroblast reproduction and embryonic development through activation of the ERK and Wnt signaling pathways, thus influencing cellular processes.

\section{Introduction}

Antioxidant of bamboo leaves (AOB) was approved as a natural food additive by the Chinese Ministry of Health in 2007. AOB may be used as a food antioxidant, preservative or flavoring in numerous types of foods. AOB has several types of bioactive components including flavonoids, lactones, and phenolic acids, however, it predominantly consists of four representative flavonoids (orientin, isoorientin, vitexin, and isovitexin). AOB is obtained from bamboo leaves and has been a focus of research due to its antioxidative activity (1). However, the dose-dependent toxicity of AOB and its impact on animal reproductive and developmental function remain unclear (2). The working principle of the genechip technique is based on hybridization between target DNA/RNA extracted from cell lines or tissues and complementary short DNA-nucleotide oligomers grafted to the solid surface of the chip $(3,4)$. Genechip has been widely used in functional genomics and investigation of pathogenic mechanisms. Mouse embryonic fibroblasts (MEF) are a type of undifferentiated cell that have the potential for infinite proliferation and totipotential differentiation $(5,6)$. MEFs have been successfully applied in a variety of biological mechanism and toxicological studies $(7,8)$. However, the effects of AOB on the reproductive toxicity of MEFs have not been reported. In the present study, MEF cells were used to detect the impact of different concentrations of AOB on MEF proliferation. Additionally, the gene expression of MEF cells was analyzed to explore the molecular mechanism through which AOB may affect the proliferation and apoptosis of MEFs. 
The present study aimed to investigate the impact of AOB on the expression of reproduction-associated proteins. These findings may provide a broader understanding of the role of AOB in the activation of the ERK and Wnt signaling pathways.

\section{Materials and methods}

Preparation of MEFs. A total of 8 pregnant ICR mice (6 weeks old; weight, $26 \pm 5 \mathrm{~g}$ ) were purchased from Zhejiang Academy of Medical Sciences (MIS20034; Zhejiang, China). All mice had free access to water and food and were maintained at $24^{\circ} \mathrm{C}$ in a humidity-controlled room with a $12-12 \mathrm{~h}$ light-dark cycle. Mice were sacrificed at day 13.5 of gestation by cervical dislocation. The body was placed into aseptic conditions following disinfection by immersion for 3-5 min in $75 \%$ ethanol. The uterine horns were dissected, briefly rinsed in PBS 3-5 times, and each embryo was separated from its placenta and embryonic sac. The uterus was cut open along the uterine membrane to remove the embryo that was covered by the membrane envelope, the embryos were washed with PBS and placed into a clean Petri dish. The tissue was finely minced using a sterile razor blade in order to facilitate pipetting. A total of $1 \mathrm{ml} 0.05 \%$ trypsin/0.02\% EDTA was added and cells were dissociated by pipetting up and down thoroughly and incubated for $5-10 \mathrm{~min}$ at $37^{\circ} \mathrm{C}$. The supernatant was aspirated and the cells were centrifuged at low-speed $(300 \mathrm{x} \mathrm{g})$ at $4^{\circ} \mathrm{C}$ for $5 \mathrm{~min}$; the supernatant was subsequently removed and the cell pellet resuspended in PBS. Cells were counted, plated in MEF medium (Bio-Rad Laboratories, Inc., Hercules, CA, USA) at a density of 35,000 cells $/ \mathrm{cm}^{2}$ in 6 -well plates and incubated at $37^{\circ} \mathrm{C}$ with $5 \% \mathrm{CO}_{2}$ for $24 \mathrm{~h}$. The medium was replaced with fresh $\mathrm{MEF}$ medium and the cells were cultured at $37^{\circ} \mathrm{C}$ with $5 \% \mathrm{CO}_{2}$. Cells were continuously passaged or frozen for future usage when they had reached $90-95 \%$ confluence. The protocol of the present study was approved by the Ethics Committee of Zhejiang University (Hangzhou, China; approval no. ZU20150324).

Cell viability (MTT) assay. AOB was provided as a kind gift from Professor Ying Zhang (Zhejiang University). Cells were seeded at $1 \times 10^{5}$ cells $/ \mathrm{ml}$ in a 24 -well plate with final AOB concentrations of $0,100,200,300,400,500$ to $800 \mu \mathrm{g} / \mathrm{ml}$, and cultured at $37^{\circ} \mathrm{C}$ with $5 \% \mathrm{CO}_{2}$ for $72 \mathrm{~h}$. Following incubation, the medium was removed and supplemented with MTT reagent (Gibco; Thermo Fisher Scientific, Inc., Waltham, MA, USA). Following incubation at $37^{\circ} \mathrm{C}$ for $4 \mathrm{~h}$, the medium was removed and $100 \mu \mathrm{l}$ DMSO was added to each well and agitated for $15 \mathrm{~min}$ at $37^{\circ} \mathrm{C}$. The cell viability percentage was assessed via spectrophotometry at $570 \mathrm{~nm}$ using an ELx800 Absorbance Reader (BioTek Instruments, Inc., Winooski, VA, USA). Based on the results of this experiment, a concentration of $400 \mu \mathrm{g} / \mathrm{ml}$ AOB was used for all subsequent experiments.

Flow cytometric analysis for apoptosis quantification. Flow cytometric analysis was used to detect the apoptotic rate of cells processed with a fluorescein isothiocyanate (FITC) Apoptosis Detection kit (BD Biosciences, San Jose, CA, USA). A total of $1 \times 10^{6}$ cells were harvested and washed twice with cold PBS. Cells were subsequently washed and incubated in buffer containing $5 \mu \mathrm{l}$ FITC-Annexin $\mathrm{V}$ and $5 \mu \mathrm{l}$ propidium iodide. Apoptosis quantification was performed using an Annexin V-FITC cellular apoptosis assay reagent kit (BD Biosciences), according to the manufacturer's protocol. Cells were subsequently collected using a FACSCalibur flow cytometer and analyzed using CellQuest Software (version 3.3, BD Biosciences).

Microarray gene expression and data analysis. The RNA samples from each group were sent to Genergy Biotechnology Co., Ltd. (Shanghai, China) for Illumina MouseWG-6 v2.0 Expression BeadChip microarray analysis (Illumina, Inc., San Diego, CA, USA). The quantile measure was used to normalize the different arrays and identify differentially-expressed genes. A fold change $\geq 12$ and $\mathrm{P}<0.05$ was considered to indicate significant differential expression of genes.

Reverse transcription-quantitative polymerase chain reaction (RT-qPCR) analysis. Total RNA was extracted using TRIzol reagent (Invitrogen; Thermo Fisher Scientific, Inc.) according to the manufacturer's protocol. Total RNA $(1 \mu \mathrm{g})$ was reverse-transcribed to cDNA using an AccuPower RT PreMix kit (Bioneer Corporation, Daejeon, Korea), with incubations performed at $37^{\circ} \mathrm{C}$ for $15 \mathrm{~min}$ followed by $85^{\circ} \mathrm{C}$ for $10 \mathrm{sec}$. Gene specific primers for the 20 mRNAs and $\beta$-actin are summarized in Table I, $\beta$-actin served as an internal control for gene expression normalization. PCR amplifications were performed using Takara master mix (Takara Biotechnology Co., Ltd., Dalian, China). For each PCR, $1 \mu \mathrm{l}$ template cDNA, equivalent to $\sim 100 \mathrm{ng}$ total RNA, was mixed with $12.5 \mu \mathrm{l}$ $2 \mathrm{X}$ SYBR-Green PCR Master mix and $0.4 \mu \mathrm{M}$ each of the forward and reverse primers in a final volume of $20 \mu \mathrm{l}$ under the following conditions: Initial enzyme activation at $95^{\circ} \mathrm{C}$ for $10 \mathrm{~min}$, amplification for 40 cycles $\left(95^{\circ} \mathrm{C}\right.$ for $30 \mathrm{sec}$ and $60^{\circ} \mathrm{C}$ for $60 \mathrm{sec}$ ), followed by a dissociation curve analysis. The relative RNA level was calculated using the $2^{\Delta \Delta \mathrm{Cq}}$ method (9).

Western blot analysis. Total proteins were extracted separately from experimental groups and control using radioimmunoprecipitation assay lysis buffer (Beyotime Institute of Biotechnology, Jiangsu, China). A total of $60 \mu \mathrm{g}$ of protein was separated by $10 \%$ SDS-PAGE. The proteins were subsequently transferred to polyvinylidene difluoride membranes and subjected to western blotting. Membranes were blocked in Tris-buffered saline and Tween-20 [150 mM NaCl, $10 \mathrm{mM}$ Tris- $\mathrm{HCl}(\mathrm{pH} 7.5)$ and $0.1 \%$ Tween-20] containing 5\% (w/v) milk at room temperature for $1.5 \mathrm{~h}$, and incubated with the primary and secondary antibodies. Membranes were incubated with the primary antibodies overnight at $4^{\circ} \mathrm{C}$. the following antibodies were used: Rabbit anti-phosphorylated extracellular signal-regulated kinase (p-ERK; 1:1,000 dilution, cat. no. NKC20314), $\beta$-catenin (1:1,000 dilution, cat. no. NKC31478), transcription factor SOX-17 (SOX17; 1:1,000 dilution, cat. no. LUY220473), calcium-binding tyrosine phosphorylation-regulated protein (CABYR; 1:1,000 dilution, cat. no. ZYS01775), cholesterol side-chain cleavage enzyme mitochondrial (P450scc; 1:1,000 dilution, cat. no. JX012004) and $\beta$-actin (1:2,000 dilution, cat. no. KC015541) (all from Sigma-Aldrich; Merck KGaA, Darmstadt, Germany). Membranes were subsequently incubated with a horseradish 
Table I. Primer sequences for reverse transcription-quantitative polymerase chain reaction analysis.

\begin{tabular}{|c|c|c|c|}
\hline Gene & Primer sequence $5^{\prime}-3^{\prime}$ & $\mathrm{Tm}$ & Length (bp) \\
\hline \multirow[t]{2}{*}{$\beta$-actin } & F: GTGACGTTGACATCCGTAAAGA & 60.3 & 245 \\
\hline & R: GCCGGACTCATCGTACTCC & 61.6 & \\
\hline \multirow[t]{2}{*}{ Cabyr } & F: AGAGGATCACCTTGGGGTACA & 61.7 & 98 \\
\hline & R: CGAAGCGACAGATGGTGGTC & 62.9 & \\
\hline \multirow[t]{2}{*}{ Pcsk4 } & F: TTGCTGGGTCTTACAAGCTACT & 60.4 & 106 \\
\hline & R: ACTGGTGAATAGAACAGGGCT & 60.1 & \\
\hline \multirow[t]{2}{*}{ Myl2 } & F: CCCTGAAGTCGAGGAGCTG & 60.9 & 114 \\
\hline & R: CTGCTGCACCTCTAAGCGA & 61.7 & \\
\hline \multirow[t]{2}{*}{ Kng2 } & F: GAAGCGTCTCACTCCCGAAG & 62.3 & 93 \\
\hline & R: GAAGAAAACGTCGCGCTACT & 60.7 & \\
\hline \multirow[t]{2}{*}{$\mathrm{Cpz}$} & F: AGAGGATCACCTTGGGGTACA & 61.7 & 98 \\
\hline & R: CGAAGCGACAGATGGTGGTC & 62.9 & \\
\hline \multirow[t]{2}{*}{ B230120H23Rik } & F: CAAACCTCAATGTGTCTCTTTGC & 60.2 & 97 \\
\hline & R: AGAGTAAAGCCTATCTCGCTGT & 60.4 & \\
\hline \multirow[t]{2}{*}{ Pla2g4b } & F: CTTCССТCATCCTCСТGCTAC & 61.1 & 145 \\
\hline & R: ACAAACTGGGTAAAGGTGATGG & 60.2 & \\
\hline \multirow[t]{2}{*}{ Rap1a } & F: CCAAAGCGGAGTCTCGCAT & 62.4 & 125 \\
\hline & R: GCCTAGCATCTTGCTTAGCTC & 60.6 & \\
\hline \multirow[t]{2}{*}{ Dhrs9 } & F: TTGCTCCGGTAACAGCAGTG & 62.4 & 105 \\
\hline & R: GTGGTCGCTTGTGTAGAAGGA & 61.7 & \\
\hline \multirow[t]{2}{*}{ Pdgfb } & F: ATGCTGGGAAAGTCATGGAAG & 60.0 & 201 \\
\hline & R: CGTGTTCTGGTCACGAGAGA & 61.2 & \\
\hline \multirow[t]{2}{*}{ Mapk12 } & F: ACCTGCACCCGATTCACAG & 62.0 & 112 \\
\hline & R: TGGCAGCATACTCCTGACCA & 62.8 & \\
\hline \multirow[t]{2}{*}{ Smc3 } & F: TCTGATCCGCTGTACTCTCCT & 61.6 & 60 \\
\hline & R: AGGCGGCAATTCAACATCCA & 62.5 & \\
\hline \multirow[t]{2}{*}{ Cxxc4 } & F: GAGAATTTCAAGTCGTGGCGA & 60.6 & 193 \\
\hline & R: CAGGTTTTCCAGTATGTGCTCC & 60.9 & \\
\hline \multirow[t]{2}{*}{ Fzd1 } & F: TTGGTTCGTCATAAGGCATCAC & 62.8 & 94 \\
\hline & R: TGTTGGCAAAGGCCATAATATCT & 61.5 & \\
\hline \multirow[t]{2}{*}{ Sfrp1 } & F: GGTTGGGAGAATCGTGACTGC & 63.0 & 299 \\
\hline & R: TAGACACACGTCGCCTCTTCA & 62.9 & \\
\hline \multirow[t]{2}{*}{ Lrp6 } & F: ATGCAGTACATTGGAGAAGGTG & 60.0 & 138 \\
\hline & R: CGTCTCTCGGCTGCCTATTT & 61.7 & \\
\hline \multirow[t]{2}{*}{ Ntrk2 } & F: TGCCCATCATTTCATTCATCCTT & 60.3 & 232 \\
\hline & R: AAAAGCGGTTTCTCACTCTCC & 60.2 & \\
\hline \multirow[t]{2}{*}{ Pla2g4e } & F: TGGTGTCCTTTATAGCCTCCTG & 59.2 & 157 \\
\hline & R: CATCTCCTGTACCTTCAAGTTGTG & 59.3 & \\
\hline \multirow[t]{2}{*}{ Fgf10 } & F: TGGTGTCCTTTATAGCCTCCTG & 58.7 & 124 \\
\hline & R: CATCTCCTGTACCTTCAAGTTGTG & 58.7 & \\
\hline \multirow[t]{2}{*}{ Pdgfra } & F: TGGTGTCCTTTATAGCCTCCTG & 61.2 & 136 \\
\hline & R: CATCTCCTGTACCTTCAAGTTGTG & 60.3 & \\
\hline
\end{tabular}

Tm, melting temperature; F, forward; R, reverse; Cabyr, calcium-binding tyrosine phosphorylation-regulated protein; Pcsk4, proprotein convertase subtilisin/kexin type 4; Myl2, myosin, light polypeptide 2; Kng2, kininogen 2; Cpz, carboxypeptidase Z; Pla2g4b, phospholipase A2 group IVB; Dhrs9, dehydrogenase/reductase 9; Pdgfb, platelet derived growth factor B; Mapk12, mitogen activated protein kinase 12; Smc3, structural maintenance of chromosomes 3; Cxxc4, CXXC finger protein 4; Fzd1, frizzled class receptor 1; Sfrp1, secreted frizzled related protein 1; Lrp6, LDL receptor related protein 6; Ntrk2, neutrotrophic tyrosine kinase receptor type 2; Pla2g4e, phospholipase A2 group IVE; Fgf10, fibroblast growth factor 10; Pdgfra, platelet derived growth factor receptor $\alpha$.

peroxidase-labeled goat anti-rabbit secondary antibody (1:5,000 dilution; cat. no. MB005, Beijing Solarbio Science and
Technology, Co., Ltd., Beijing, China) at $37^{\circ} \mathrm{C}$ for $2 \mathrm{~h}$. Protein signals were detected using Electrochemiluminescence 


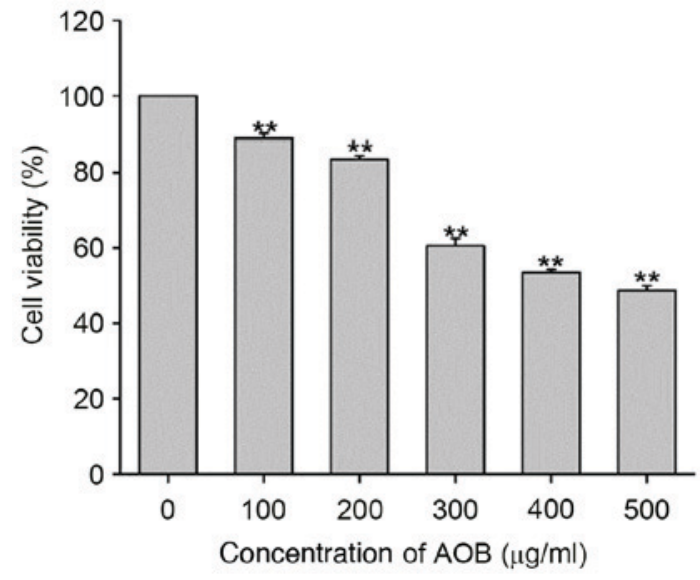

Figure 1. Effects of increasing AOB concentration on mouse embryonic fibroblast cell proliferation. ${ }^{* *} \mathrm{P}<0.01$ vs. $0 \mu \mathrm{g} / \mathrm{ml} \mathrm{AOB}$. AOB, antioxidant of bamboo leaves.

Plus Western Blotting Detection system (GE Healthcare Bio-Sciences, Pittsburgh, PA, USA). Target bands were analyzed for gray levels using ImageJ 1.37 (National Institutes of Health, Bethesda, MD, USA).

Bioinformatic analysis. The functional annotation of differentially-expressed genes was performed according to the Gene Ontology (GO) databases (www.geneontology.org). The GO category was classified using hypergeometric distribution, and the Benjamini and Hochberg $(\mathrm{BH})$ false discovery rate (FDR) algorithm was used to adjust the resulting P-values. GO enrichment was considered to be significant if the FDR values were $\leq 0.05$. Pathway analysis was used to identify the significant pathways of the differentially-expressed genes according to the Kyoto Encyclopedia of Genes and Genomes (KEGG; www.genome.jp/kegg). Similarly, hypergeometric distribution, followed by $\mathrm{BH}$ multiple testing correction, was performed to select the significant pathways, and the threshold of significance was defined as $\mathrm{P}=0.05$.

Statistical analysis. All data were analyzed using SPSS 17.0 software (SPSS, Inc., Chicago, IL, USA). Experiments were performed in triplicate. Data are expressed as the mean \pm standard deviation. One-way analysis of variance was performed to compare the differences among the groups. Pairwise comparisons among multiple sets of data were analyzed using the least significant difference test. $\mathrm{P}<0.05$ was considered to indicate a statistically significant difference.

\section{Results}

$A O B$ effectively inhibits $M E F$ cell proliferation. In order to measure the cytotoxic effects of AOB, MEF cells were treated with increasing concentrations of AOB for $72 \mathrm{~h}$. Subsequently, cell viability was measured using an MTT assay. The results of the present study indicated that AOB inhibited the cell growth of MEF cells more effectively at increased concentrations (Fig. 1). The $\mathrm{IC}_{50}$ value of AOB for MEF cells was $429.8 \mu \mathrm{g} / \mathrm{ml}$. Compared with the control group, $50 \%$ of MEF cells were killed by a $400 \mu \mathrm{g} / \mathrm{ml}$ concentration of AOB. Therefore, the concentration of $400 \mu \mathrm{g} / \mathrm{ml}$ was selected for the follow-up experiments.
A

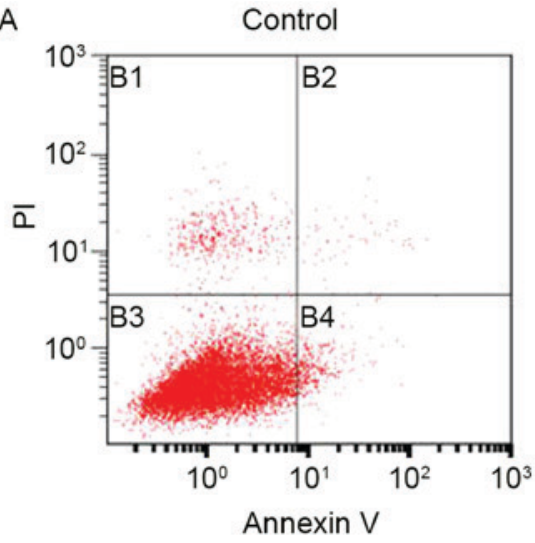

B
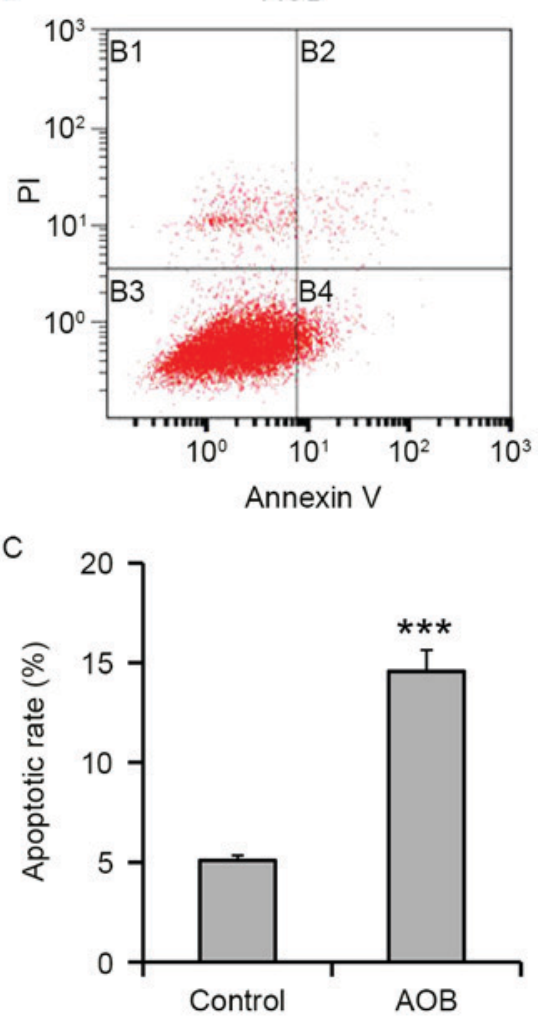

Figure 2. Apoptosis rates in mouse embryonic fibroblast cells, analyzed using flow cytometry. The images demonstrate the flow cytometric analysis of apoptosis in (A) control and (B) AOB-treated cells. (C) Histograms illustrating apoptosis assay results. Annexin $\mathrm{V}^{+} \mathrm{PI}^{+}$denotes the late-stage apoptotic cells (B2), and Annexin $\mathrm{V}^{+} \mathrm{PI}^{-}$denotes the early-stage apoptotic cells (B4). ${ }^{* * *} \mathrm{P}<0.001$ vs. control. AOB, antioxidant of bamboo leaves; PI, propidium iodide.

Treatment with $A O B$ results in increased apoptosis. In order to address the cytotoxic effects of the selected treatment, $400 \mu \mathrm{g} / \mathrm{ml} \mathrm{AOB}$-treated cells were analyzed for their apoptosis phenotype. According to the results, treatment with $400 \mu \mathrm{g} / \mathrm{ml}$ AOB in MEF cells for $72 \mathrm{~h}$ significantly increased the apoptotic population to $14.57 \pm 1.06 \%$ ( $\mathrm{P}<0.001$; Fig. 2 ), whereas the control group contained an apoptotic population of $5.09 \pm 0.26 \%$.

Hierarchical cluster analysis. Hierarchical cluster analysis was performed to allow for the rapid detection of alterations in the levels of gene expression in addition to identification of important genes, as presented in Fig. 3. Pathway analysis was 


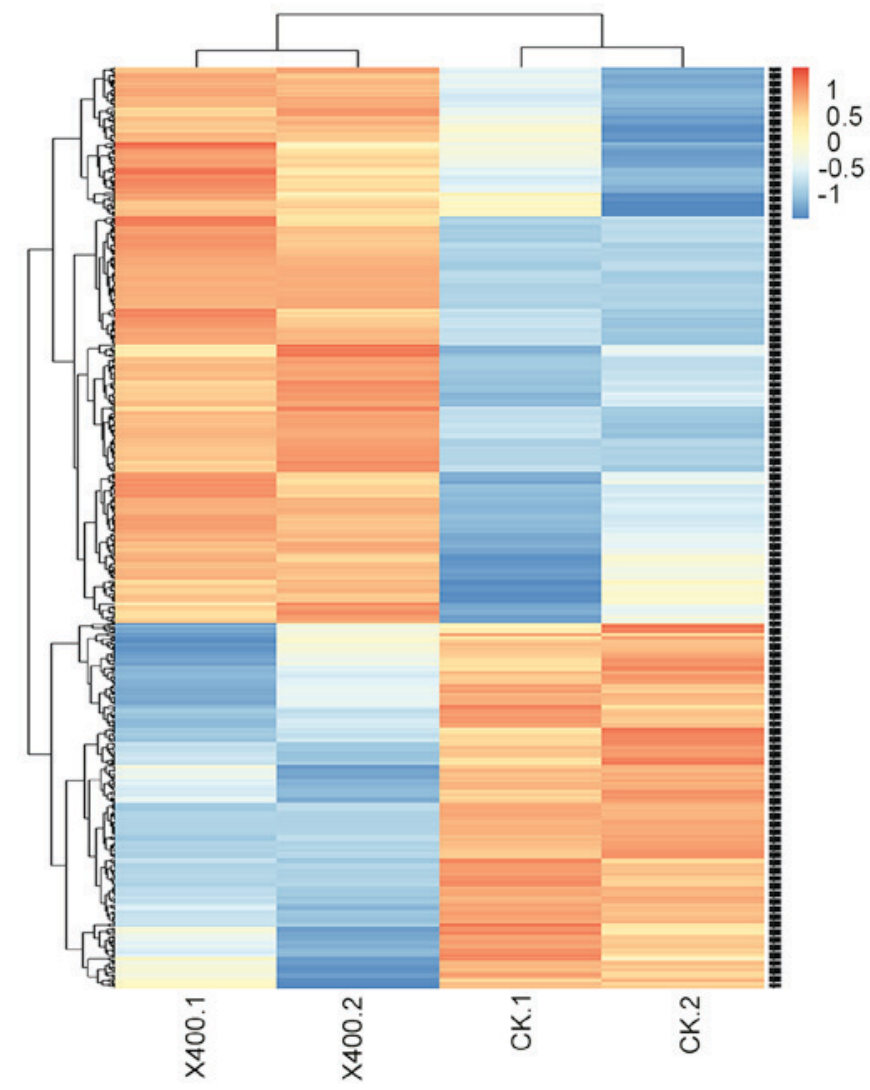

Figure 3. Cluster analysis of differentially-expressed genes. CK.1, blank control group 1; CK.2, blank control group 2; X400.1, $400 \mu \mathrm{g} / \mathrm{ml} \mathrm{AOB}$ treated group 1; X400.2, $400 \mu \mathrm{g} / \mathrm{ml} \mathrm{AOB}$ treated group 2; AOB, antioxidant of bamboo leaves.

conducted to identify the significant pathways of the differentially-expressed gene sets, according to KEGG. Through a selection process, the differentially-expressed genes were determined to be primarily involved in metabolic pathways (the metabolism of exogenous substances, sugars, amino acids, glutathione and steroid hormones), apoptotic pathways, and those relevant to reproductive function.

Confirmation of gene expression by RT-qPCR analysis. In order to verify the data obtained by the microarray analysis (data not shown), RT-qPCR analysis was performed on 20 differentially-expressed genes. The results of the RT-qPCR analysis were consistent with those from the microarray analysis. As presented in Fig. 4, treatment with AOB in MEF cells resulted in the downregulation of dehydrogenase/reductase 9 , phospholipase A2 group IVE and platelet derived growth factor $\mathrm{B}$, while the other 17 genes were upregulated.

Effects of $A O B$ on the mitogen-activated protein kinase $(M A P K) / E R K$ and the proto-oncogene Wnt (Wnt) pathways. As presented in Fig. 5, treatment with AOB notably increased the expression of p-ERK, and the ERK pathway inhibitor U0126 suppressed the expression of p-ERK in AOB-treated MEF cells. Additionally, the expression of $\beta$-catenin, SOX17, CABYR and P450scc was increased following treatment with $\mathrm{AOB}$, although it was decreased by treatment with $\mathrm{AOB}+\mathrm{U} 0126$ and $\mathrm{AOB}+\mathrm{Dickkopf}-$ related protein 1 (DKK1; a Wnt pathway inhibitor).
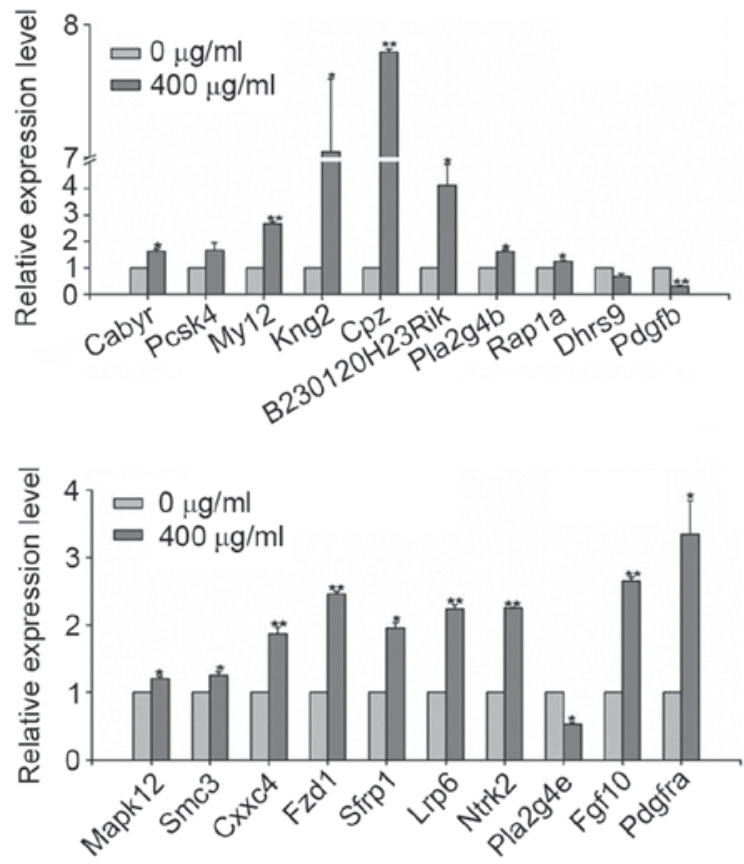

Figure 4. Reverse transcription-quantitative polymerase chain reaction analysis of differentially-expressed genes. ${ }^{*} \mathrm{P}<0.05,{ }^{* *} \mathrm{P}<0.01 \mathrm{vs} .0 \mu \mathrm{g} / \mathrm{ml}$ AOB. AOB, antioxidant of bamboo leaves. Cabyr, calcium-binding tyrosine phosphorylation-regulated protein; Pcsk4, proprotein convertase subtilisin/kexin type 4; Myl2, myosin, light polypeptide 2; Kng2, kininogen v2; Cpz, carboxypeptidase Z; Pla2g4b, phospholipase A2 group IVB; Dhrs9, dehydrogenase/reductase 9; Pdgfb, platelet derived growth factor B; Mapk12, mitogen activated protein kinase 12 ; Smc3, structural maintenance of chromosomes 3; Cxxc4, CXXC finger protein 4; Fzd1, frizzled class receptor 1; Sfrp1, secreted frizzled related protein 1; Lrp6, LDL receptor related protein 6; Ntrk2, neutrotrophic tyrosine kinase receptor type 2; Pla2g4e, phospholipase A2 group IVE; Fgf10, fibroblast growth factor 10; Pdgfra, platelet derived growth factor receptor $\alpha$.
A

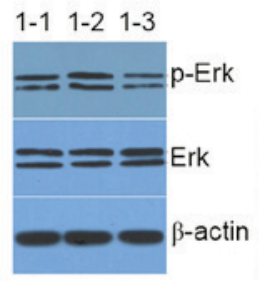

B

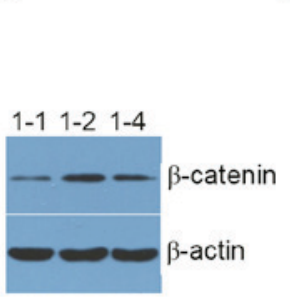

C 1-1 1-2 1-3 1-4

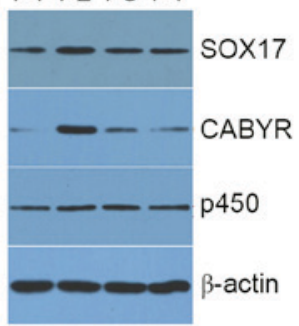

Figure 5. Western blot analysis of the expression level of (A) p-ERK and ERK, (B) $\beta$-catenin, and (C) P450, CABYR and SOX17 in mouse embryonic fibroblast cells. 1-1, blank control group; 1-2, AOB group; 1-3, $\mathrm{AOB}+\mathrm{U} 0216$ group; 1-4, $\mathrm{AOB}+\mathrm{DKK} 1$ group; $\mathrm{AOB}$, antioxidant of bamboo leaves; p-, phosphorylated; ERK, extracellular signal-regulated kinase; P450, cholesterol side-chain cleavage enzyme mitochondrial; CABYR, calcium-binding tyrosine phosphorylation-regulated protein; SOX17, transcription factor SOX-17.

\section{Discussion}

MAPK signaling pathways are involved in mediating cell growth, survival and death processes. Three of the MAPK members are c-Jun N-terminal kinase, p38 and ERK (10-12). ERK is a widely-expressed protein kinase intracellular signaling molecule which is involved in the regulation of meiosis, mitosis, and postmitotic functions in differentiated 
cells (13). A number of different stimuli, including growth factors, cytokines, viral infection, ligands for heterotrimeric $\mathrm{G}$ protein-coupled receptors, transforming agents and carcinogens, may activate the ERK pathway (14). ERK serves a prominent role in the bone morphogenetic protein (BMP) and ERK/MAPK signaling pathways (15). The phosphorylation of ERK activates the BMP pathway by interacting with mothers against decapentaplegic homolog 1, 5 and 8. In addition, p-ERK exerts a function in the process of apoptosis by interacting with son of sevenless homolog and ribosomal protein S6 kinase $\alpha-1$ (16).

In the results of western blot analysis performed in the present study, the expression of p-ERK significantly increased in AOB-treated MEF cells compared with control MEF cells. No notable changes in ERK expression occurred between the experimental and control groups. The results indicated that AOB may promote the phosphorylation of ERK and activate the ERK signaling pathway. Additionally, adding ERK inhibitor U0126 to AOB-treated cells downregulated the expression of $\mathrm{p}$-ERK. The results of the present study demonstrated that AOB may enhance the activation of the ERK pathway, thereby influencing cellular processes.

The Wnt/ $\beta$-catenin pathway facilitates an accumulation of $\beta$-catenin in the cytoplasm and its eventual translocation into the nucleus to act as a transcriptional coactivator of transcription factors (17). The results of the present study demonstrated that the expression of $\beta$-catenin increased markedly in AOB-treated MEF cells. Dkk1 is an antagonistic inhibitor of the Wnt signaling pathway that acts by isolating the low-density lipoprotein receptor-related protein 6 co-receptor so that it is unable to activate the Wnt signaling pathway (18). DKK1 has been demonstrated to antagonize the $\mathrm{Wnt} / \beta$-catenin pathway via a reduction in $\beta$-catenin expression (18). It was previously observed that treatment with DDK1 led to a decrease in $\beta$-catenin expression in AOB-treated MEF cells (19). These previous results suggested that AOB may activate the Wnt signaling pathway by enhancing $\beta$-catenin expression, thus influencing cellular processes. CABYR and SOX17 proteins are associated with the morphological and molecular maturational processes of spermatozoa (20). P450scc, encoded by the CYP11A1 gene, is able to convert cholesterol to pregnenolone to initiate steroidogenesis $(7,21)$. In the results of the presents study, the expression of CABYR, SOX17 and P450scc was upregulated in AOB-treated MEF cells, demonstrating that AOB may affect the regulation of reproductive function. In addition, U0126 and DDK1 inhibited the expression of CABYR, SOX17 and P450scc in AOB-treated MEF cells. The results of the present study demonstrated that these proteins were involved in the ERK and Wnt signaling pathways, and that AOB markedly upregulated the expression of CABYR, SOX17 and P450scc.

In conclusion, the present study established an MEF cell model to investigate the effects of $\mathrm{AOB}$ on the expression of genes associated with murine reproduction and embryonic development. The results of the present study provided evidence that AOB may impact the expression of proteins associated with reproduction. Additionally, the present findings suggested that AOB may enhance the activation of the ERK and Wnt signaling pathways, thereby influencing cellular processes. Elucidating the AOB role on signaling pathways in the MEF cell model may provide useful information for clinical reproduction and embryonic development.

\section{Acknowledgements}

The Research Fund for Giant Panda Breeding of Chengdu (grant no. CPF2012-15) and the China Agriculture Research System (grant no. CARS-05).

\section{References}

1. Lu B, Wu X, Shi J, Dong Y and Zhang Y: Toxicology and safety of antioxidant of bamboo leaves. Part 2: Developmental toxicity test in rats with antioxidant of bamboo leaves. Food Chem Toxicol 44: 1739-1743, 2006.

2. Ma X, Wang E, Lu Y, Wang Y, Ou S and Yan R: Acylation of antioxidant of bamboo leaves with fatty acids by lipase and the acylated derivatives' efficiency in the inhibition of acrylamide formation in fried potato crisps. PLoS One 10: e0130680, 2015.

3. Shi XC, Liu XQ, Xie XL, Xu YC and Zhao ZX: Gene chip array for differentiation of mycobacterial species and detection of drug resistance. Chin Med J (Engl) 125: 3292-3297, 2012.

4. Lu L, Gao Y, Xu M, Ge RC and Lu L: Gene expression profiles associated with osteoblasts differentiated from bone marrow stromal cells. Asian Pac J Trop Med 7: 344-351, 2014.

5. Rieske P, Krynska B and Azizi SA: Human fibroblast-derived cell lines have characteristics of embryonic stem cells and cells of neuro-ectodermal origin. Differentiation 73: 474-483, 2005.

6. Ngo C, Nicco C, Leconte M, Chéreau C, Arkwright S, VacherLavenu MC, Weill B, Chapron C and Batteux F: Protein kinase inhibitors can control the progression of endometriosis in vitro and in vivo. J Pathol 222: 148-157, 2010.

7. Slominski A, Zbytek B, Nikolakis G, Manna PR, Skobowiat C, Zmijewski M, Li W, Janjetovic Z, Postlethwaite A, Zouboulis CC and Tuckey RC: Steroidogenesis in the skin: Implications for local immune functions. J Steroid Biochem Mol Biol 137: 107-123, 2013

8. Wang N, Zhang W, Cui J, Zhang H, Chen X, Li R, Wu N, Chen X, Wen S, Zhang J, et al: The piggyBac transposon-mediated expression of SV40 T antigen efficiently immortalizes mouse embryonic fibroblasts (MEFs). PLoS One 9: e97316, 2014.

9. Livak KJ and Schmittgen TD: Analysis of relative gene expression data using real-time quantitative PCR and the 2(-Delta Delta C(T)) method. Methods 25: 402-408, 2001.

10. Bandyopadhyay M, Bishop CP and Bidwai AP: The Conserved MAPK Site in E(spl)-M8, an effector of Drosophila notch signaling, controls repressor activity during eye development. PLoS One 11: e0159508, 2016.

11. Li W, Ma Z, Ma J, Li X, Xu Q, Duan W, Chen X, Lv Y, Zhou S, Wu E, et al: Hydrogen peroxide mediates hyperglycemia-induced invasive activity via ERK and p38 MAPK in human pancreatic cancer. Oncotarget 6: 31119-31133, 2015.

12. Aye IL, Jansson T and Powell TL: TNF- $\alpha$ stimulates System A amino acid transport in primary human trophoblast cells mediated by p38 MAPK signaling. Physiol Rep 3: pii: e12594, 2015.

13. Williams KA, Zhang M, Xiang S, Hu C, Wu JY, Zhang S, Ryan M, Cox AD, Der CJ, Fang B, et al: Extracellular signal-regulated kinase (ERK) phosphorylates histone deacetylase 6 (HDAC6) at serine 1035 to stimulate cell migration. J Biol Chem 288: 33156-33170, 2013.

14. Ghanian MH,Farzaneh Z, Barzin J,Zandi M,Kazemi-Ashtiani M, Alikhani M, Ehsani M and Baharvand H: Nanotopographical control of human embryonic stem cell differentiation into definitive endoderm. J Biomed Mater Res A 103: 3539-3553, 2015.

15. Kim HK, Kim MG and Leem KH: Osteogenic activity of collagen peptide via ERK/MAPK pathway mediated boosting of collagen synthesis and its therapeutic efficacy in osteoporotic bone by back-scattered electron imaging and microarchitecture analysis. Molecules 18: 15474-15489, 2013.

16. Zhang YH, Cheng F, Du XT, Gao JL, Xiao XL, Li N, Li SL and Dong de L: GDF11/BMP11 activates both smad1/5/8 and smad2/3 signals but shows no significant effect on proliferation and migration of human umbilical vein endothelial cells. Oncotarget 7: 12063-12074, 2016. 
17. Bikorimana E, Lapid D, Choi H and Dahl R: Retroviral infection of murine embryonic stem cell derived embryoid body cells for analysis of hematopoietic differentiation. J Vis Exp 20: e52022, 2014.

18. Liu L, Miao XP and Lin DX: The challenge and opportunity in the post genome-wide association study era. Zhonghua Yu Fang Yi Xue Za Zhi 46: 198-201, 2012 (In Chinese).

19. Atlasi Y, Mowla SJ, Ziaee SA and Bahrami AR: OCT-4, an embryonic stem cell marker, is highly expressed in bladder cancer. Int J Cancer 120: 1598-1602, 2007.
20. Naaby-Hansen S, Mandal A, Wolkowicz MJ, Sen B, Westbrook VA, Shetty J, Coonrod SA, Klotz KL, Kim YH, Bush LA, et al: CABYR, a novel calcium-binding tyrosine phosphorylation-regulated fibrous sheath protein involved in capacitation. Dev Biol 242: 236-254, 2002.

21. Tee MK, Abramsohn M, Loewenthal N, Harris M, Siwach S, Kaplinsky A, Markus B, Birk O, Sheffield VC, Parvari R, et al: Varied clinical presentations of seven patients with mutations in CYP11A1 encoding the cholesterol side-chain cleavage enzyme, P450scc. J Clin Endocrinol Metab 98: 713-720, 2013. 